\title{
Clinical and radiological results of high offset tri-lock bone preservation stem in unilateral primary total hip arthroplasty at a minimum follow-up of 3 years
}

\author{
Linbo Peng ${ }^{\dagger}$, Jun $\mathrm{Ma}^{\dagger}$, Yi Zeng, Yuangang Wu, Haibo Si and Bin Shen ${ }^{*}$ (i)
}

\begin{abstract}
Background: Although the high offset Tri-Lock bone preservation stem (BPS) was used widely, few studies explored the clinical and radiological results. The purpose of this study was to determine the clinical and radiological results of high offset Tri-Lock BPS in unilateral primary total hip arthroplasty (THA) at a minimum follow-up of 3 years.

Methods: 55 patients who underwent cementless THA with high offset Tri-lock BPS from 2017 to 2018 were followed for a minimum follow-up of 3 years. Patients were assessed clinically for complications, Harris hip score (HHS), Western Ontario and McMaster Universities Osteoarthritis Index (WOMAC), and Oxford Hip Score (OHS). Femoral offset (FO), acetabular offset (AO), hip offset (HO), HO difference, and leg length discrepancy (LLD) were measured on the anteroposterior (AP) pelvic radiograph. Standard pelvic AP and lateral radiographs were used to evaluate for evidence of bone ingrowth, stem subsidence, stem alignment, radiolucent line around the stem, osteolysis, loosening, ectopic ossification, and femoral stress shielding.

Results: No patients reported complications during hospitalization nor the follow-up period. At a mean follow-up of 42.5 months, the mean HHS, WOMAC, and OHS scores showed a significant improvement from preoperative to the latest follow-up. No patients reported thigh pain. No revision nor sign of radiographic loosening had been detected. The high offset Tri-Lock BPS significantly improved the FO and HO postoperatively. HO difference and LLD were balanced postoperatively. No sign of stem subsidence, radiolucent line, osteolysis, loosening, ectopic ossification, nor severe stress shielding (more than grade 3-4) were observed at the latest follow-up.
\end{abstract}

Conclusion: The high offset Tri-Lock BPS demonstrated excellent clinical and radiographic outcomes at a minimum follow-up of 3 years. $\mathrm{HO}$ difference and LLD between legs decreased significantly and achieved balance postoperatively. Long-term follow-up is required for a definitive conclusion.

Keywords: Total hip arthroplasty, High offset, Stem, Hip function, Offset, Leg length discrepancy

*Correspondence: shenbin_1971@163.com

${ }^{\dagger}$ Linbo Peng and Jun Ma contributed equally to this study

Department of Orthopedics, Orthopedic Research Institute, West China Hospital, Sichuan University, 37\# Guoxue Road, Chengdu 610041, Sichuan Province, People's Republic of China

\section{Introduction}

Total hip arthroplasty (THA) is an effective method to treat end-stage hip disease for relieving the pain and improving joint activity and the quality of life $[1,2]$. The conventional standard-length femoral stem is a common prosthesis and associated with a high survival rate at a follow-up of nearly 30 years [3-5]. The demand for original author(s) and the source, provide a link to the Creative Commons licence, and indicate if changes were made. The images or other third party material in this article are included in the article's Creative Commons licence, unless indicated otherwise in a credit line to the material. If material is not included in the article's Creative Commons licence and your intended use is not permitted by statutory regulation or exceeds the permitted use, you will need to obtain permission directly from the copyright holder. To view a copy of this licence, visit http://creativecommons.org/licenses/by/4.0/. The Creative Commons Public Domain Dedication waiver (http://creativeco mmons.org/publicdomain/zero/1.0/) applies to the data made available in this article, unless otherwise stated in a credit line to the data. 
THA surgery in younger patients is increasing in recent years $[6,7]$. Young patients face a higher risk of revision because of higher activity levels than elderly patients [8]. The lifespan of the cementless prosthesis is limited, and young patients may inevitably encounter revision surgery in later life [9]. The median time to revision for patients younger than 60 years was 4.4 years [10]. The conventional standard-length femoral stem may increase the difficulty of revision surgery due to osseointegration and deficiencies in the preservation of the moral bone stock $[11,12]$. Besides, thigh pain, stress shielding, aseptic loosening, and periprosthetic fracture remain a matter of concern $[13,14]$.

Recently, shorter bone preservation stems (BPS) were widely used in THA because of specific advantages [15]. The novel design of Tri-Lock BPS, such as a reduced lateral shoulder, a thin geometry, and a shorter length, conserves native bone stock during THA [11]. Tri-Lock BPS has a highly porous and roughened coating (Gription), which leads to mechanical integrity and long-term biological fixation [16]. Furthermore, the short stem might reduce stress shielding and thigh pain by changing the transmission of stem load [17].

Tri-Lock BPS manages soft tissue laxity without affecting leg length by choosing different offset stems, including standard and high offset stems [18]. Femoral offset (FO) is defined by the distance between the center of the femoral head and a line bisecting the long axis of the femur [19]. Restoring the offset and leg length is crucial for optimal function and long-term outcomes following THA [20]. An appropriate offset is associated with a better soft-tissue tension, a better range of motion (ROM), and a lower dislocation rate [21-23]. Femoral stems comprise different offset versions, which effectively restore the biomechanical hip [24]. The high offset stem has been confirmed to decrease the risk of dislocation than the standard offset stem after THA [25]. However, high offset stems are subject to increase torsional loading about the long axis of the implant and increase the loosening rate in cemented high offset stems [26].

Although the high offset BPS was used widely, few studies explored the clinical and radiological results. Given that any design of an implant demands a careful follow-up, we conduct this specific study on outcomes of high offset Tri-Lock BPS in unilateral primary THA. The purpose of this study was to determine the clinical and radiological results of high offset Tri-Lock BPS in unilateral primary THA at a minimum follow-up of 3 years.

\section{Methods}

\section{Inclusion and exclusion criteria}

The inclusion criterion was as follows: (1) patients who underwent primary THAs in our institution without
Table 1 Preoperative characteristics

\begin{tabular}{ll}
\hline Parameters & \\
\hline Number of hips (patients) & $55(55)$ \\
Age (years) & $49.8(25-73)$ \\
Sex (female: male) & $13(23.6 \%): 42(76.4 \%)$ \\
BMI (kg/m $\left.{ }^{2}\right)$ & $23.8(17.9-33.8)$ \\
Surgery side (left: right) & $20: 35$ \\
Main diagnosis (n, percentage) & \\
Primary OA & $4(7.3 \%)$ \\
DDH & $10(18.2 \%)$ \\
ONFH & $29(52.7 \%)$ \\
Femoral neck fracture & $1(1.8 \%)$ \\
OA secondary to childhood hip problems & $2(3.6 \%)$ \\
OA secondary to infection & $7(12.7 \%)$ \\
Post-traumatic osteoarthritis & $2(3.6 \%)$ \\
Dorr type (n, percentage) & \\
A & $10(18.2 \%)$ \\
B & $43(78.2 \%)$ \\
C & $2(3.6 \%)$ \\
Mean follow-up (months) & $42.5(36-48)$ \\
\hline
\end{tabular}

BMI, body mass index; OA, Osteoarthritis; DDH, dysplasia of the hip; ONFH, osteonecrosis of the femoral head

contraindication; (2) patients using high offset Tri-lock BPS (Depuy, Johnson \& Johnson, Warsaw, IN, USA) in the THA surgery; (3) patients had enough radiological and clinical data; (4) patients had a contralateral native hip;

The exclusion criterion was as follows: (1) patients with one-stage bilateral THA; (2) patients who were diagnosed as dysplasia of the hip (DDH) Crowe type III or IV; (3) patients who had disqualified or incomplete radiological data; (4) patients who were lost to follow up; (5) patients had a contralateral hip with prosthesis or deformity.

\section{Study population}

This retrospective study was approved by the clinical trials and biomedical ethics committee of West China Hospital and written informed consents were obtained from all the participants. From April 2017 to April 2018, 80 patients (87 hips) were identified who underwent cementless THAs with high offset Tri-lock BPS in our institution by five experienced senior surgeons. Of all the 80 patients, 7 patients (14 hips) were one-stage bilateral THAs, 6 patients (6 hips) had disqualified radiological data, 5 patients ( 5 hips) were lost to follow up, 6 patients (6 hips) had a contralateral hip with prosthesis or deformity, and 1 patient died for cholangiocarcinoma, which was unrelated to the THA surgery. Thus, 55 hips in 55 patients comprised the study population. Patients' 
demographic and characteristic data were collected from the electronic medical data (Table 1).

\section{Surgical technique}

Preoperative templating in the standard anteroposterior (AP) pelvic radiograph was used to identify appropriate acetabular size and location. Appropriate femoral stem size and neck length were confirmed to fit the geometry of the femur and acquired proper hip offset $(\mathrm{HO})$ and leg length discrepancy (LLD) then. Tri-lock BPS dual offset options provided surgeons with standard and high offset stems to restore femoral offset without affecting leg length. We only included patients who use high offset Tri-lock BPS during the THA in our study. All patients were treated with general anesthesia. Pinnacle acetabular cup systems (Depuy, Johnson \& Johnson, Warsaw, IN, USA) were used in the surgeries, including $32 / 36 \mathrm{~mm}$ ceramic heads and appropriate liner. A polyethylene/ ceramic liner accommodating a ceramic head was used in all the patients. All the surgeries were performed through the posterolateral (PL) approach or direct anterior approach (DAA). Conventional prophylactic intravenous antibiotics and thromboprophylaxis were used postoperatively. Furthermore, patients were encouraged to take active exercise in bed after surgery. On the second day postoperatively, partial weight training with the help of a walking aid was conducted after confirming the AP pelvic and lateral X-rays. We educated patients to walk with a walking stick two weeks postoperatively. They gradually change to full weight-bearing training four weeks postoperatively. Patients were followed up at two weeks, four weeks, three months, six months, 12 months, and annually postoperatively.

\section{Clinical assessment}

Electronic medical records were evaluated to obtain all the in-hospital complications. Complications such as wound infection, periprosthetic infection (PJI), deep venous thrombosis (DVT), pulmonary embolism (PE), periprosthetic fracture (PFF), dislocation, and persistent thigh pain were recorded during the follow-up. Reoperation and revision for any reason were recorded during the follow-up period. Harris hip score (HHS), Western Ontario and McMaster Universities Osteoarthritis Index (WOMAC), Oxford Hip Score (OHS) were used to assess the clinical function of the patients preoperatively and at the latest follow-up. OHS, WOMAC and HHS were classic and common functional hip scores and widely used to report clinical outcomes following THA $[27,28]$.

\section{Radiographic measurement}

All the radiographs were collected and measured by two independent reviewers who were unrelated to the surgeries and blinded to the clinical outcomes. Another measurement was performed by the same two observers one week after the initial measurement, blinded to the previous results. Radiographic assessment was measured on the AP pelvic radiograph with the lower limb in $15^{\circ}$ internal rotation using Syngo (Siemens Medical Solutions, Forchheim, Germany) preoperatively, second day postoperatively, and at the latest follow-up. The preoperative geometry of proximal femur was classified by the classification system of Dorr et al. (Fig. 1) [29]. The calcar-to-canal ratio was calculated by the calcar width (the middle level of the lesser trochanter) divided by the canal width (10 cm below the lesser trochanter) (Fig. 1) [30]. Therefore, the geometry of proximal femur was divided into type A (0-0.500), type B $(0.501-0.750)$, and type C (0.751-1.000) according to the calcar-to-canal ratio [31]. Other radiographic parameters were measured and calculated, including FO, acetabular offset (AO), $\mathrm{HO}, \mathrm{HO}$ difference, and LLD in the AP pelvic radiograph preoperatively and second day postoperatively (Fig. 1) [32]. The FO was measured as the vertical distance from the center of rotation of the femoral head (COR) and the ipsilateral anatomical femoral axis [32]. The AO was measured as the vertical distance from the COR and the vertical line passing through the ipsilateral teardrop [32]. The HO was

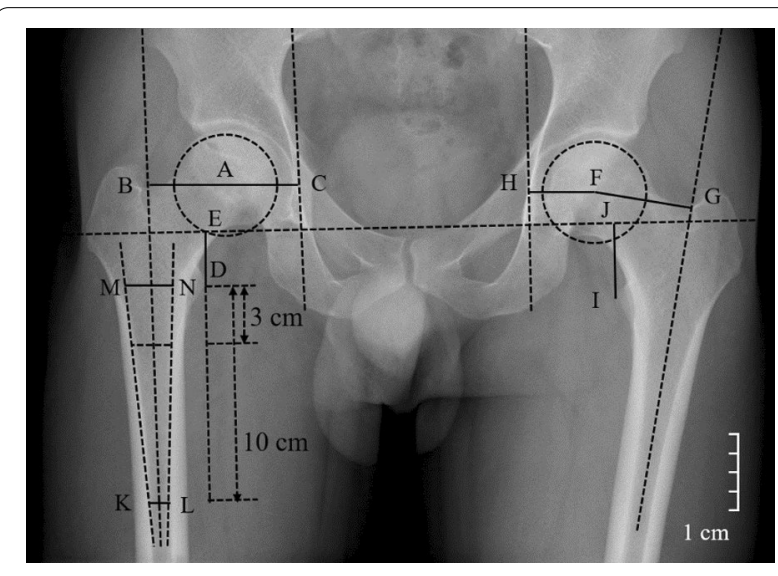

Fig. 1 Radiographic measurement. The calcar width was measured as the middle level of the lesser trochanter (line MN). The canal width was measured as $10 \mathrm{~cm}$ below the lesser trochanter (line $\mathrm{KL}$ ). The calcar-to-canal ratio was calculated as line $\mathrm{KL}$ divided by line $M N$, which was used for the Dorr classification. The femoral offset (FO) was measured as the vertical distance from the center of COR and the ipsilateral anatomical femoral axis (line $A B$ and line FG). The acetabular offset $(\mathrm{AO})$ was measured as the vertical distance from the COR and the vertical line passing through the ipsilateral teardrop (line $\mathrm{AC}$ and line $\mathrm{FH}$ ). The hip offset $(\mathrm{HO})$ was calculated as the sum of $F O$ and $A O$ (line $A B+$ line $A C$ and line $F G$ + line $F H$ ). Leg length discrepancy (LLD) was calculated as the difference between the bilateral vertical line from the most prominent part of the trochanter to the transteardrop line (difference of line ED and line Jl) 
calculated as the sum of $\mathrm{FO}$ and $\mathrm{AO}$ [32]. The $\mathrm{HO}$ difference was calculated as the difference between the bilateral HO. LLD was calculated as the difference between the bilateral vertical line from the most prominent part of the trochanter to the transteardrop line (TTL) [33]. Standard pelvic AP and lateral radiographs postoperatively and at the latest follow-up were used to evaluate for evidence of bone ingrowth, stem subsidence, stem alignment, radiolucent line around the stem, osteolysis, loosening, ectopic ossification, and femoral stress shielding [34]. The bone ingrowth was identified according to Engh et al. $[35,36]$. The stem subsidence was identified if the femoral stem settled more than $3 \mathrm{~mm}$ between the immediate postoperative radiographs and those at the last follow-up [35]. The stem alignment was defined as neutral (deviation from the axis of the femoral shaft within $5^{\circ}$ ), valgus (lateral deviation more than $5^{\circ}$ ), or varus (medial deviation more than $5^{\circ}$ ) according to the previous study (Fig. 2) [37]. The radiolucent line was defined as regular, linear, lucent areas around the stem [11]. Osteolysis was identified as at least $5 \mathrm{~mm}$ irregularly shaped radiolucent at the bone-stem interface [36, 38]. Ectopic ossification was identified according to the Brooker classification [39]. Femoral stress shielding was identified according to a modification of the criteria defined by Engh and Bobyn and divided into four degrees [34].

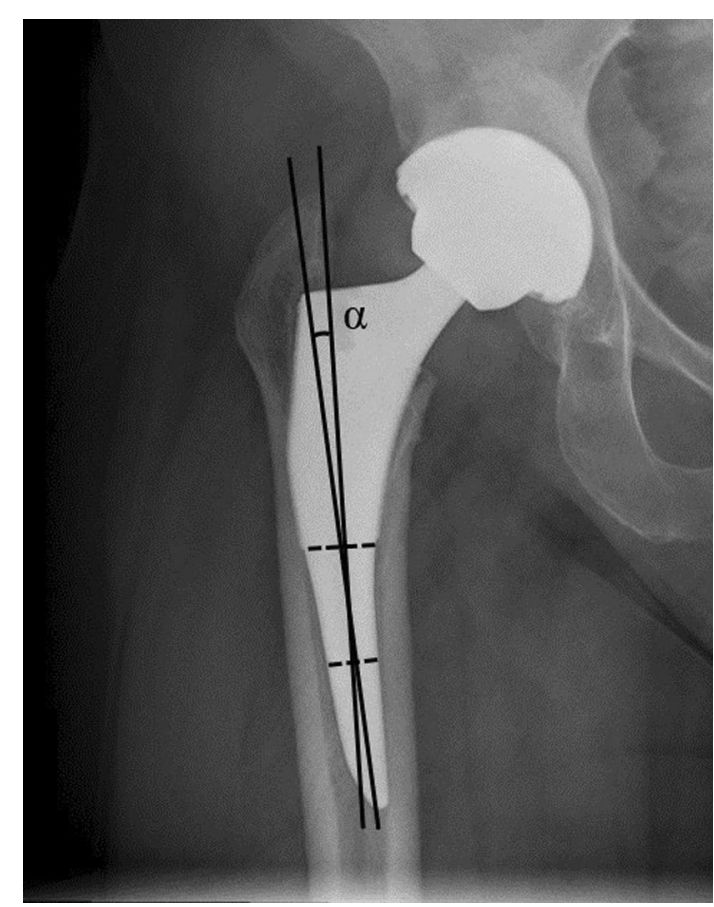

Fig. 2 The stem alignment was defined as neutral (deviation from the axis of the femoral shaft within $5^{\circ}$ ), valgus (lateral deviation more than $5^{\circ}$ ), or varus (medial deviation more than $5^{\circ}$ )

\section{Statistical analysis}

The data were analyzed using SPSS 26.0 (IBM, Armonk, USA). A two-tailed paired t-test was used to assess the differences between the FO, HO, HO difference, and LLD preoperatively and on the second day postoperatively. A two-tailed paired $\mathrm{t}$-test was used to assess the HHS, WOMAC, OHS scores. Intraclass correlation coefficients (ICC) were used to measure intraobserver and interobserver reliability with a two-way random model for absolute agreement. P-value $<0.05$ was defined as statistical significance.

\section{Results}

\section{General information}

The mean age of the study population was 49.8 years (range 25-73). Our study included 13 females (23.6\%) and 42 males (76.4\%). Patients' mean body mass index (BMI) was $23.8 \mathrm{~kg} / \mathrm{m}^{2}$ (range 17.9-33.8). Twenty patients had left side surgeries, while 35 patients had right. The most common diagnosis was osteonecrosis of the femoral head (ONFH), which was found in 29 (52.7\%) patients. According to the Dorr classification, ten patients (18.2\%) were classified as Dorr A, 43 patients $(78.2 \%)$ as Dorr B, and two patients (3.6\%) as Dorr C. And the mean follow-up was 42.5 months (range 36-48) (Table 1).

Thirty patients $(54.5 \%)$ underwent THA through a PL approach, while 25 patients (45.5\%) through a DAA approach. The mean stem size was 3.3\# (range 0\#-8\#). Nineteen patients $(34.5 \%)$ received $32 \mathrm{~mm}$ Ceramic femoral heads, while 36 patients $(65.5 \%)$ received $36 \mathrm{~mm}$ ones. The bearing surface was ceramic-on-ceramic in 50 patients (90.9\%) and ceramic-on-polyethylene in 5 patients (9.1\%). Fifty-three patients $(96.4 \%)$ had a neutral stem alignment, one patient (1.8\%) had valgus, and one (1.8\%) had varus (Table 2).

\section{Clinical results}

During the follow-up, no patients reported any complications, including wound infection, PJI, DVT, PE, PFF, dislocation, nor persistent thigh pain. Furthermore, there were no patients who encounter any revision surgery or reoperation. The survival rate of high offset Tri-Lock BPS at the latest follow-up was $100 \%$.

The HHS showed a significant improvement from $48.13 \pm 9.66$ preoperatively to $96.84 \pm 5.60$ at the latest follow-up $(p<0.01)$. At the latest follow-up, all the patients $(100 \%)$ had excellent or good function results on HHS. The WOMAC total score decreased from $50.04 \pm 9.40$ preoperatively to $3.27 \pm 3.36$ at the latest follow-up $(p<0.01)$. Besides, the OHS decreased from 
Table 2 Surgical and prosthesis data

\begin{tabular}{lc}
\hline Parameters & \\
\hline Surgical approach ( $n$, percentage) & $30(54.5 \%)$ \\
PL & $25(45.5 \%)$ \\
DAA & $3.3(0-8)$ \\
Stem size & \\
Ceramic femoral head size (n, percentage) & $19(34.5 \%)$ \\
32 mm & $36(65.5 \%)$ \\
36 mm & \\
Bearing surface & $50(90.9 \%)$ \\
Ceramic-on-ceramic & $5(9.1 \%)$ \\
Ceramic-on-polyethylene & \\
Stem alignment & $53(96.4 \%)$ \\
$\quad$ Neutral & $1(1.8 \%)$ \\
Valgus & $1(1.8 \%)$ \\
Varus & \\
\hline
\end{tabular}

$\mathrm{PL}$, posterolateral approach; DAA, direct anterior approach

Table 3 Clinical results

\begin{tabular}{llll}
\hline Parameters & Preoperative & At latest follow-up & $\boldsymbol{p}$ value \\
\hline HHS & $48.13 \pm 9.66$ & $96.84 \pm 5.60$ & $<0.01$ \\
Excellent (90-100) & 0 & 50 & \\
Good (80-89) & 0 & 5 & \\
Fair (70-79) & 0 & 0 & \\
Poor (<70) & 55 & 0 & $<0.01$ \\
WOMAC total score & $50.04 \pm 9.40$ & $3.27 \pm 3.36$ & $<0.01$ \\
Pain & $8.87 \pm 2.42$ & $1.04 \pm 1.28$ & $<0.01$ \\
Stiffness & $2.96 \pm 1.20$ & $0.67 \pm 0.70$ & $<0.01$ \\
Function & $38.20 \pm 9.87$ & $1.56 \pm 1.76$ & $<0.01$ \\
OHS score & $36.15 \pm 8.80$ & $15.33 \pm 3.12$ & \\
\hline
\end{tabular}

HHS, Harris hip score; WOMAC, Western Ontario and McMaster Universities Osteoarthritis Index; OHS, Oxford Hip Score

$36.15 \pm 8.80$ preoperatively to $15.33 \pm 3.12$ at the latest follow-up $(p<0.01)$ (Table 3$)$.

\section{Radiographic results}

The ICCs for intraobserver and interobserver agreement among all the radiographic parameters were excellent $(>0.8)$. The mean FO significantly improved from $43.2 \pm 9.1 \mathrm{~mm}$ to $48.2 \pm 7.4 \mathrm{~mm}(p<0.01)$. The HO improved from $81.0 \pm 8.6 \mathrm{~mm}$ to $83.4 \pm 8.5 \mathrm{~mm}$ $(p<0.01)$. The HO difference between legs decreased from $2.8 \pm 7.0 \mathrm{~mm}$ preoperatively to $0.4 \pm 5.7 \mathrm{~mm}$ postoperatively $(p<0.01)$. Besides, the LLD decreased from $7.4 \pm 8.4 \mathrm{~mm}$ to $4.3 \pm 3.3 \mathrm{~mm}(p<0.01)$. On the second day postoperatively, 53 patients (96.4\%) limited LLD within $10 \mathrm{~mm}$, and all the patients limited LLD within $20 \mathrm{~mm}$ (Table 4).
Table 4 Radiographic results

\begin{tabular}{llll}
\hline Parameters & Pre-op & 2nd day post-op & p value \\
\hline FO (mm) & $43.2 \pm 9.1$ & $48.2 \pm 7.4$ & $<0.01$ \\
HO (mm) & $81.0 \pm 8.6$ & $83.4 \pm 8.5$ & $<0.01$ \\
HO difference $(\mathrm{mm})$ & $2.8 \pm 7.0$ & $0.4 \pm 5.7$ & $<0.01$ \\
LLD $(\mathrm{mm})$ & $7.4 \pm 8.4$ & $4.3 \pm 3.3$ & $<0.01$ \\
0-10 mm & $41(74.5 \%)$ & $53(96.4 \%)$ & \\
$10-20 \mathrm{~mm}$ & $10(18.2 \%)$ & $2(3.6 \%)$ & \\
$>20 \mathrm{~mm}$ & $4(7.3 \%)$ & $0(0.0 \%)$ & \\
\hline
\end{tabular}

FO, femoral offset; HO, hip offset; LLD, leg length discrepancy

The radiographic evaluation confirmed bone ingrowth in all the patients. Fifty-three patients $(96.4 \%)$ had a neutral stem alignment. Only one patient $(1.8 \%)$ had a valgus stem, and another (1.8\%) had a varus stem. Those two patients also achieved good clinical and radiographic outcomes at the latest follow-up. There were no radiographic signs of stem subsidence, radiolucent line, osteolysis, loosening, or ectopic ossification. Stress shielding was observed in 55 hips (100\%). Among them, 32 patients (58.2\%) were classified in grade 1 and 23 patients (41.8\%) were classified in grade 2 (Fig. 3). No patients detected severe stress shielding (grade 3 or 4 ) in our study.

\section{Discussion}

This study mainly evaluated the clinical and radiological results of high offset Tri-Lock BPS in unilateral primary THA at a minimum follow-up of 3 years. No patients reported any complications related to the stem during hospitalization nor the follow-up period. At a mean follow-up of 42.5 months, The HHS, WOMAC, and OHS scores showed a significant improvement. No patients reported thigh pain. The survival rate of high offset TriLock BPS at a minimum follow-up of 3 years was $100 \%$ as no patients suffered any revision nor radiographic loosening. Besides, the high offset Tri-Lock BPS significantly improved the FO and $\mathrm{HO}$ postoperatively. HO difference and LLD were balanced postoperatively. At the latest follow-up, no signs of stem subsidence, radiolucent line, osteolysis, loosening, or ectopic ossification were observed.

Some previous studies found that the Tri-Lock BPS offers excellent postoperative function at a mid to long follow-up, which were similar to our results $[15,18$, 40]. A recent study found no comparable significance between Tri-Lock BPS and conventional long stem in terms of HHS, VAS, and WOMAC [11]. $96.4 \%$ of patients had a neutral stem alignment postoperatively in our study. Patients with valgus or varus stem alignment did not get any inferior clinical or radiological results, which was consistent with the previous study [18]. Ulive et al. 


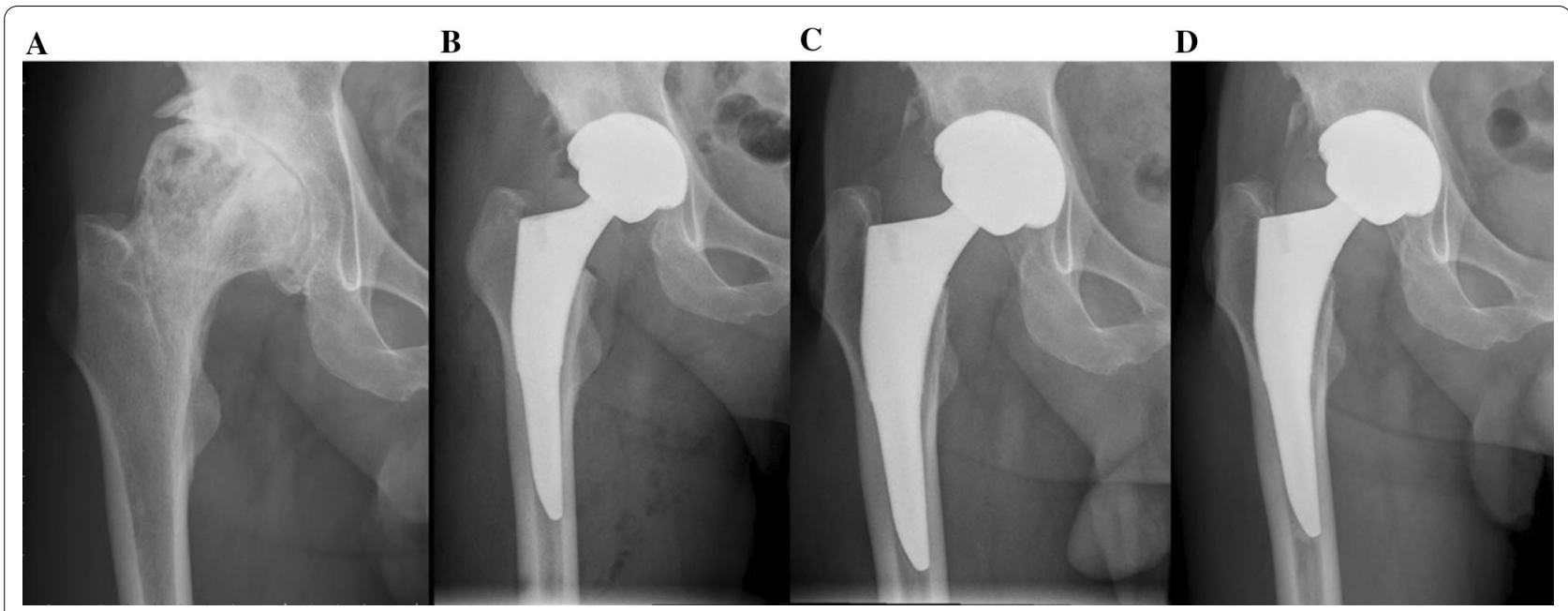

Fig. 3 Anteroposterior pelvic radiograph of a 57-year-old male who was diagnosed as OA secondary to infection. The images show the progression of stress shielding at preoperative (a), second day postoperatively (b), 1 year (c), and 4 years post-operatively (d)

confirmed that varus and valgus in terms of stem alignment did not undermine implants' survival and clinical and patient-reported outcomes [18].

No patients reported any complications, including dislocation during the follow-up period in our study. The other two studies reported postoperative dislocation with Tri-Lock BPS stem during the follow-up period $[11,18]$. However, they failed to report if high offset stems were used in the dislocation patients. In a retrospective study involving more than ten hundred patients, $49 \%$ utilized high offset stems. There were $51(0.41 \%)$ patients who occurred dislocations postoperatively. Of those patients who occurred hip dislocations, only 2 (4\%) patients utilized standard offset stems [25]. The use of a high offset stem may decrease the risk of dislocation.

In our study, no patient experienced persistent thigh pain. This low incidence of thigh pain was consistent with previous studies $[15,18]$. In the study of Guo et al., the rate of thigh pain was $0 \%$ at a mean follow-up of 48 months [11]. Two meta-analyses emphasized that short stems decreased the incidence of thigh pain [41, 42]. This superiority of short stem might be related to the reduced proximal stress shielding and the development of excellent mechanical transmission [43].

In this study, the specific stem was stable and showed no signs of stem subsidence. Some previous literature reported the outcomes of Tri-Lock BPS regardless of standard or high-offset version stems $[11,15,18,40]$. Albers et al. [15] reported a $99.2 \%$ stem survival rate of Tri-Lock BPS at a minimum 4-year follow-up. Ulivi et al. [18] reported that the survival rate of Tri-Lock BPS was $99 \%$ at a mean follow-up of 5.7 years. One patient received revision surgery for hip dislocation [18]. Zhen et al. [40] investigated patients who use Tri-Lock BPS in Dorr type $\mathrm{C}$ femoral bone. At a mean follow-up of 5.5 years, no signs of stem subsidence were observed. The high survival rate may be related to the unique design and the roughened porous coating [15]. Guo et al. found that one patient required revision because of recurrent dislocation and no occurrences of prosthesis subsidence in the cohort of 104 hips at a mean follow-up of 2 years [11]. The proximal porous coating maintains mechanical integrity under shear, compression, torsion, and tension force [16]. A shorter length and narrow distal segment allowed a better proximal stress transfer and avoided distal stress overload [18]. Extended osteotomy may be needed for the femoral stem removal during potential future revision THA [44]. However, no revision surgery had been detected in our cohort. We need to notice the potential risk of extended osteotomy in future revision THA.

No patients detected severe (grade 3 or 4) stress shielding in our study. Our results were consistent with previous studies. Zhen et al. [40] found that no patients exhibited severe stress shielding at a mean follow-up of 5.5 years. In the study of Guo et al., 9\% of patients detected grade 3 stress shielding at a mean follow-up of 48 months [11]. Tri-Lock BPS stem can stock the proximal femoral bone from loss and get the primary stability by a metaphyseal fixation. The unique design reduced the incidence of the distal medullary cavity being invaded and stress shielding [41].

$\mathrm{HO}$ and leg length reconstruction postoperatively is crucial for an additive effect on clinical outcomes [20]. Restoration of leg length and offset correlate reduced trochanteric pain syndrome postoperatively [45]. A 
postoperative unbalanced offset between legs was associated with hip abductor muscle weakness and may increase gait asymmetry in the sagittal plane [21]. Leg length discrepancy is one of the most common causes of litigation following THA [46]. The use of a high offset stem offered better restoration of the offset [47]. Although the high offset stem was used widely, few studies have quantified the improvement of offset and LLD by the specific stem design. We found that the FO and HO were significantly improved from preoperative to postoperative in our study. HO difference and LLD between legs decreased significantly and achieved balance postoperatively. The use of high offset stems helped surgeons achieving excellent $\mathrm{HO}$ and LLD in our cohort. Incavo et al. found $85 \%$ of patients had no clinical leg length discrepancy postoperatively using a high offset stem in primary THA [48]. However, they did not provide a quantitative measurement of the improvement on offset and LLD. Yao et al. [49] revealed Tri-Lock stem restores the offset and LLD. But they did not provide the proportion of dual offset stems, including standard and high offset stems [49]. A meta-analysis including 320 patients reported no significant differences in the FO and LLD after primary THA using short stem versus conventional stem [42]. This was the first study that has quantified the improvement of offset and LLD using a high offset TriLock stem. In order to restore offset, using a standard offset stem may lengthen the neck and thus lead to leg length discrepancy for patients with native high offset. The Tri-Lock BPS is available with standard and high offset versions for all the stem sizes. The high offset stem provides direct lateralization, increasing offset without sacrificing leg length. The excellent functional outcomes of the patients in our study might be attributed to the restoration of offset and LLD by high offset Tri-Lock stem.

The strengths of this study were its completeness of the clinical and radiological results of high offset Tri-Lock BPS at a minimum follow-up of 3 years. Moreover, we have quantified the improvement of offset and LLD firstly by using this specific stem.

There are also some limitations to our study. First, the sample size of this study was relatively small and lacked a control group. Second, this was a retrospective study and the risk of selection bias cannot be avoided. Third, all the patients were followed for not more than 4 years. Further studies are required to detect long-term clinical and radiological results of high offset Tri-Lock BPS.

\section{Conclusions}

The high offset Tri-Lock BPS demonstrated excellent clinical and radiographic outcomes at a minimum followup of 3 years. There were no radiographic signs of stem subsidence, radiolucent line, osteolysis, loosening, or ectopic ossification. HO difference and LLD between legs decreased significantly and achieved balance postoperatively. Extended follow-up is required to assess the durability of this stem.

\section{Acknowledgements \\ Linbo Peng and Jun Ma contributed equally to this study.}

\section{Authors' contributions}

$\mathrm{BS}$ and $\mathrm{JM}$ conceived and designed the analysis. LP and YW collected the data. YZ and HS performed the analysis. LP wrote the manuscript. All authors read and approved the final manuscript.

\section{Funding \\ This research did not receive any specific grant from funding agencies in public, commercial, or not-for-profit sectors.}

\section{Availability of data and materials}

The authors confirm that the data supporting the findings of this study are available within the article.

\section{Declarations}

\section{Ethics approval and consent to participate}

This study was approved by the ethics committee of the West China Hospital, and written consent was obtained from all patients. All included patients provided informed consent.

\section{Consent for publication}

All authors provided publish consent.

\section{Competing interests}

No support from any organization for the submitted work; No financial relationships with any organization that might have an interest in the submitted work in the previous 3 years; No author is an employee of a company that provided funding or whose products are mentioned in our article; No other relationships or activities that could appear to have influenced the submitted work.

Received: 13 September 2021 Accepted: 11 October 2021

Published online: 24 October 2021

\section{References}

1. Dimitriou D, Antoniadis A, Flury A, Liebhauser M, Helmy N. Total hip arthroplasty improves the quality-adjusted life years in patients who exceeded the estimated life expectancy. J Arthroplasty. 2018:33(11):3484-9. https://doi.org/10.1016/j.arth.2018.07.005.

2. Ethgen $O$, Bruyère $O$, Richy $F$, Dardennes $C$, Reginster JY. Health-related quality of life in total hip and total knee arthroplasty. A qualitative and systematic review of the literature. J Bone Jt Surg. 2004;86(5):963-74. https://doi.org/10.2106/00004623-200405000-00012.

3. McLaughlin JR, Lee KR. Total hip arthroplasty with an uncemented tapered femoral component in patients younger than 50 years of age: a minimum 20-year follow-up study. J Arthroplasty. 2016;31 (6):1275-8. https://doi.org/10.1016/j.arth.2015.12.026.

4. Streit MR, Lehner B, Peitgen DS, Innmann MM, Omlor GW, Walker T, Merle C, Moradi B. What is the long-term (27- to 32-year) survivorship of an uncemented tapered titanium femoral component and survival in patients younger than 50 years? Clin Orthop Relat Res. 2020;478(6):128391. https://doi.org/10.1097/corr.0000000000001203.

5. Valkering LJJ, Biemond JE, van Hellemondt GG. A wedge-shaped uncemented femoral component: survivorship in patients younger than 50 years at a mean follow-up of 22 years. J Arthroplasty. 2018;33(10):322630. https://doi.org/10.1016/j.arth.2018.06.009.

6. Kuijpers MFL, Hannink G, van Steenbergen LN, Schreurs BW. Total hip arthroplasty in young patients in The Netherlands: trend analysis of $>19,000$ primary hip replacements in the Dutch arthroplasty register. J 
Arthroplasty. 2018;33(12):3704-11. https://doi.org/10.1016/j.arth.2018.08. 020.

7. Skyttä ET, Jarkko L, Antti E, Huhtala H, Ville R. Increasing incidence of hip arthroplasty for primary osteoarthritis in 30- to 59-year-old patients. Acta Orthop. 2011;82(1):1-5. https://doi.org/10.3109/17453674.2010.548029.

8. Kurtz SM, Lau E, Ong K, Zhao K, Kelly M, Bozic KJ. Future young patient demand for primary and revision joint replacement: national projections from 2010 to 2030. Clin Orthop Relat Res. 2009;467(10):2606-12. https:// doi.org/10.1007/s11999-009-0834-6.

9. Te Stroet MA, Rijnen WH, Gardeniers JW, van Kampen A, Schreurs BW. Satisfying outcomes scores and survivorship achieved with impaction grafting for revision THA in young patients. Clin Orthop Relat Res. 2015:473(12):3867-75. https://doi.org/10.1007/s1 1999-015-4293-y.

10. Bayliss LE, Culliford D, Monk AP, Glyn-Jones S, Prieto-Alhambra D, Judge A, Cooper C, Carr AJ, Arden NK, Beard DJ, Price AJ. The effect of patient age at intervention on risk of implant revision after total replacement of the hip or knee: a population-based cohort study. Lancet (London, England). 2017;389(10077):1424-30. https://doi.org/10.1016/s0140-6736(17) 30059-4.

11. Guo J, Tan J, Peng L, Song Q, Kong HR, Wang P, Shen HY. Comparison of tri-lock bone preservation stem and the conventional standard corail stem in primary total hip arthroplasty. Orthop Surg. 2021. https://doi.org/ 10.1111/os.12946.

12. Kim YH, Park JW, Kim JS. Short-term results of ultra-short anatomic vs ultra-short non-anatomic proximal loading uncemented femoral stems. J Arthroplasty. 2018;33(1):149-55. https://doi.org/10.1016/j.arth.2017.07. 042.

13. Jo WL, Lee YK, Ha YC, Park MS, Lyu SH, Koo KH. Frequency, developing time, intensity, duration, and functional score of thigh pain after cementless total hip arthroplasty. J Arthroplasty. 2016;31(6):1279-82. https://doi. org/10.1016/j.arth.2015.12.016.

14. Won SH, Park JW, Lee YK, Ha YC, Koo KH. No clinically important differences in thigh pain or bone loss between short stems and conventionallength stems in THA: a randomized clinical trial. Clin Orthop Relat Res. 2021;479(4):767-77. https://doi.org/10.1097/corr.0000000000001505.

15. Albers A, Aoude AA, Zukor DJ, Huk OL, Antoniou J, Tanzer M. Favorable results of a short, tapered, highly porous, proximally coated cementless femoral stem at a minimum 4-year follow-up. J Arthroplasty. 2016;31(4):824-9. https://doi.org/10.1016/j.arth.2015.08.020.

16. Jasty M, Bragdon C, Burke D, O'Connor D, Lowenstein J, Harris WH. In vivo skeletal responses to porous-surfaced implants subjected to small induced motions. J Bone Jt Surg. 1997;79(5):707-14. https://doi.org/10. 2106/00004623-199705000-00010.

17. Liang HD, Yang WY, Pan JK, Huang HT, Luo MH, Zeng LF, Liu J. Are short-stem prostheses superior to conventional stem prostheses in primary total hip arthroplasty? A systematic review and meta-analysis of randomised controlled trials. BMJ Open. 2018;8(9): e021649. https://doi, org/10.1136/bmjopen-2018-021649.

18. Ulivi M, Orlandini LC, Meroni V, Lombardo MDM, Peretti GM. Clinical performance, patient reported outcome, and radiological results of a short, tapered, porous, proximally coated cementless femoral stem: results up to seven years of follow-up. J Arthroplasty. 2018;33(4):1133-8. https://doi. org/10.1016/j.arth.2017.11.046.

19. Lecerf G, Fessy MH, Philippot R, Massin P, Giraud F, Flecher X, Girard J, Mertl P, Marchetti E, Stindel E. Femoral offset: anatomical concept, definition, assessment, implications for preoperative templating and hip arthroplasty. OTSR. 2009;95(3):210-9. https://doi.org/10.1016/j.otsr.2009. 03.010 .

20. Innmann MM, Maier MW, Streit MR, Grammatopoulos G, Bruckner T, Gotterbarm T, Merle C. Additive influence of hip offset and leg length reconstruction on postoperative improvement in clinical outcome after total hip arthroplasty. J Arthroplasty. 2018;33(1):156-61. https://doi.org/ 10.1016/j.arth.2017.08.007.

21. Sato H, Maezawa K, Gomi M, Kajihara H, Hayashi A, Maruyama Y, Nozawa M, Kaneko K. Effect of femoral offset and limb length discrepancy on hip joint muscle strength and gait trajectory after total hip arthroplasty. Gait Posture. 2020;77:276-82. https://doi.org/10.1016/j.gaitpost.2020.02.008.

22. Matsushita A, Nakashima Y, Jingushi S, Yamamoto T, Kuraoka A, Iwamoto Y. Effects of the femoral offset and the head size on the safe range of motion in total hip arthroplasty. J Arthroplasty. 2009;24(4):646-51. https://doi.org/10.1016/j.arth.2008.02.008.
23. Takao M, Nishii T, Sakai T, Sugano N. Postoperative limb-offset discrepancy notably affects soft-tissue tension in total hip arthroplasty. J Bone Jt Surg. 2016;98(18):1548-54. https://doi.org/10.2106/jbjs.15.01073.

24. Biggi S, Banci L, Tedino R, Capuzzo A, Cattaneo G, Tornago S, Camera A. Restoring global offset and lower limb length with a 3 offset option double-tapered stem. BMC Musculoskelet Disord. 2020;21(1):646. https:// doi.org/10.1186/s12891-020-03674-8.

25. Vigdorchik JM, Sharma AK, Elbuluk AM, Carroll KM, Mayman DJ, Lieberman JR. High offset stems are protective of dislocation in high-risk total hip arthroplasty. J Arthroplasty. 2021;36(1):210-6. https://doi.org/10. 1016/j.arth.2020.07.016.

26. Hellman EJ, Capello WN, Feinberg JR. Omnifit cementless total hip arthroplasty. A 10-year average followup. Clin Orthop Relat Res. 1999;364:16474. https://doi.org/10.1097/00003086-199907000-00022.

27. Rahman L, Muirhead-Allwood SK, Alkinj M. What is the midterm survivorship and function after hip resurfacing? Clin Orthop Relat Res. 2010;468(12):3221-7. https://doi.org/10.1007/s11999-010-1438-X.

28. van der Wees PJ, Wammes JJ, Akkermans RP, Koetsenruijter J, Westert GP, van Kampen A, Hannink G, de Waal-Malefijt M, Schreurs BW. Patientreported health outcomes after total hip and knee surgery in a Dutch University Hospital Setting: results of twenty years clinical registry. BMC Musculoskelet Disord. 2017;18(1):97. https://doi.org/10.1186/ s12891-017-1455-y.

29. Dorr LD, Faugere MC, Mackel AM, Gruen TA, Bognar B, Malluche HH. Structural and cellular assessment of bone quality of proximal femur. Bone. 1993;14(3):231-42. https://doi.org/10.1016/8756-3282(93)90146-2.

30. Nakaya R, Takao M, Hamada H, Sakai T, Sugano N. Reproducibility of the Dorr classification and its quantitative indices on plain radiographs. OTSR. 2019;105(1):17-21. https://doi.org/10.1016/j.otsr.2018.11.008.

31. Park CW, Eun HJ, Oh SH, Kim HJ, Lim SJ, Park YS. Femoral stem survivorship in dorr type a femurs after total hip arthroplasty using a cementless tapered wedge stem: a matched comparative study with type B femurs. J Arthroplasty. 2019;34(3):527-33. https://doi.org/10.1016/j.arth.2018.11. 004.

32. Parry MC, Povey J, Blom AW, Whitehouse MR. Comparison of acetabular bone resection, offset, leg length and post operative function between hip resurfacing arthroplasty and total hip arthroplasty. J Arthroplasty. 2015;30(10):1799-803. https://doi.org/10.1016/j.arth.2015.04.030.

33. Ranawat CS, Rodriguez JA. Functional leg-length inequality following total hip arthroplasty. J Arthroplasty. 1997;12(4):359-64. https://doi.org/ 10.1016/s0883-5403(97)90190-x.

34. Engh CA, Bobyn JD. The influence of stem size and extent of porous coating on femoral bone resorption after primary cementless hip arthroplasty. Clin Orthop Relat Res. 1988;231:7-28.

35. Engh CA, Bobyn JD, Glassman AH. Porous-coated hip replacement. The factors governing bone ingrowth, stress shielding, and clinical results. J Bone Jt Surg. 1987;69(1):45-55. https://doi.org/10.1302/0301-620x.69b1. 3818732.

36. Engh CA, Massin P, Suthers KE. Roentgenographic assessment of the biologic fixation of porous-surfaced femoral components. Clin Orthop Relat Res. 1990;257:107-28.

37. De Martino I, De Santis V, D'Apolito R, Sculco PK, Cross MB, Gasparini G. The synergy cementless femoral stem in primary total hip arthroplasty at a minimum follow-up of 15 years. Bone Jt J. 2017;99-b(1):29-36. https:// doi.org/10.1302/0301-620x.99b1.Bjj-2016-0231.R1.

38. Goetz DD, Smith EJ, Harris WH. The prevalence of femoral osteolysis associated with components inserted with or without cement in total hip replacements. A retrospective matched-pair series. J Bone Jt Surg. 1994;76(8):1121-9. https://doi.org/10.2106/00004623-199408000-00002.

39. Brooker AF, Bowerman JW, Robinson RA, Riley LH Jr. Ectopic ossification following total hip replacement Incidence and a method of classification. J Bone Jt Surg. 1973;55(8):1629-32.

40. Zhen P, Chang Y, Yue H, Chen H, Zhou S, Liu J, He X. Primary total hip arthroplasty using a short bone-conserving stem in young adult osteoporotic patients with Dorr type C femoral bone. J Orthop Surg Res. 2021;16(1):17. https://doi.org/10.1186/s13018-020-01985-z.

41. Zhang Z, Xing Q, Li J, Jiang Z, Pan Y, Hu Y, Wang L. A comparison of short-stem prostheses and conventional stem prostheses in primary total hip arthroplasty: a systematic review and meta-analysis of randomized controlled trials. Ann Transl Med. 2021;9(3):231. https://doi.org/10.21037/ atm-20-4043. 
42. Huo SC, Wang F, Dong $\sqcup$, Wei W, Zeng JQ, Huang HX, Han QM, Duan RQ. Short-stem prostheses in primary total hip arthroplasty: A meta-analysis of randomized controlled trials. Medicine. 2016;95(43): e5215. https://doi. org/10.1097/md.0000000000005215.

43. Pogliacomi F, Schiavi P, Grappiolo G, Ceccarelli F, Vaienti E. Outcome of short versus conventional stem for total hip arthroplasty in the femur with a high cortical index: a five year follow-up prospective multicentre comparative study. Int Orthop. 2020;44(1):61-8. https://doi.org/10.1007/ s00264-019-04335-9.

44. Tarity TD, Xiang W, Gkiatas I, Meyers KN, Malahias MA, Rodriguez JA, Wright TM, Sculco PK. Extended trochanteric osteotomy closure performed before or after canal preparation and stem impaction does not affect axial stability. J Arthroplasty. 2021. https://doi.org/10.1016/j.arth. 2021.07.010.

45. Worlicek M, Messmer B, Grifka J, Renkawitz T, Weber M. Restoration of leg length and offset correlates with trochanteric pain syndrome in total hip arthroplasty. Sci Rep. 2020;10(1):7107. https://doi.org/10.1038/ s41598-020-62531-9.

46. Hofmann AA, Skrzynski MC. Leg-length inequality and nerve palsy in total hip arthroplasty: a lawyer awaits! Orthopedics. 2000:23(9):943-4.
47. Danesh-Clough T, Bourne RB, Rorabeck CH, McCalden R. The mid-term results of a dual offset uncemented stem for total hip arthroplasty. J Arthroplasty. 2007;22(2):195-203. https://doi.org/10.1016/j.arth.2006.04 006.

48. Incavo SJ, Havener T, Benson E, McGrory BJ, Coughlin KM, Beynnon BD. Efforts to improve cementless femoral stems in THR: 2-to 5-year follow-up of a high-offset femoral stem with distal stem modification (Secur-Fit Plus). J Arthroplasty. 2004;19(1):61-7. https://doi.org/10.1016/j.arth.2003. 09.006.

49. Yao M, Wang Y, Wei C, Han Y, Li H. Greater increase in femoral offset with use of collum femoris-preserving stem than Tri-Lock stem in primary total hip arthroplasty. J Int Med Res. 2020;48(5):300060520925999. https://doi. org/10.1177/0300060520925999.

\section{Publisher's Note}

Springer Nature remains neutral with regard to jurisdictional claims in published maps and institutional affiliations.
Ready to submit your research? Choose BMC and benefit from:

- fast, convenient online submission

- thorough peer review by experienced researchers in your field

- rapid publication on acceptance

- support for research data, including large and complex data types

- gold Open Access which fosters wider collaboration and increased citations

- maximum visibility for your research: over $100 \mathrm{M}$ website views per year

At BMC, research is always in progress.

Learn more biomedcentral.com/submissions 